\title{
NOVE MANIFESTOS PARA AJUDAR A PENSAR O HUMANO NA PSICOLOGIA ${ }^{1}$
}

\author{
Josemar de Campos MACIEL ${ }^{2}$
}

\begin{abstract}
O Professor Mauro Martins Amattuzzi é bem conhecido no Brasil, especialmente por aqueles que trabalham com pesquisa fenomenológica em psicologia. Portador de vasta cultura humanística, ele veio para o campo da psicologia com esse traço e suas inquietudes decorrentes. Formou-se em Psicologia pela PUC de São Paulo e é doutor em Filosofia da Educação pela Unicamp com uma tese que se transformou no livro $O$ Resgate da Fala Autêntica (Campinas: Papirus: 1989). Após ter sido docente do Instituto de Psicologia da USP, vem trabalhando há alguns anos na PUC-Campinas na área de pesquisa fenomenológica, dedicando-se sucessivamente à psicologia da comunidade, a questões clínicas e relativas à vivência religiosa e, enfim, a novos campos fronteiriços da psicologia.
\end{abstract}

O livro em questão é constituído de nove textos, precedidos por uma apresentação, de autoria da Dra. Vera Engler Cury, também da PUC-Campinas. Dos capítulos do livro, dois são inéditos: o IV, "Pesquisa do vivido" (págs. 53-60) e o IX, "Processos Humanos" (págs. 117-131). Os outros são reedições revisadas de artigos, conferências e apresentações em congresso ou cursos já publicados anteriormente. O livro não contém gráficos, apenas dois quadros explicativos, um de esquema (pág. 101) e outro de realce de conteúdo, à pág. 102.
Os temas dos capítulos podem ser brevemente esboçados como segue: após a breve apresentação, são discutidos conceitos referentes ao significado da palavra e da elaboração humana do sentido da realidade, para o resgate de uma atitude humanista no exercício da psicologia (capítulo l: "Humanismo e Psicologia"). Em seguida, o Autor enfoca a questão da linguagem, a partir do filósofo Merleau-Ponty, para propor reflexões sobre o significado da palavra como âmbito de comunicação de vivências autênticas (capítulo II: "Silêncio e Palavra").

No capítulo III, ele discute modelos de investigação da experiência humana, reivindicando mais espaço sobretudo para a experiência cotidiana, mítica, poética ("Investigação do humano"). Em seguida, no capítulo IV, discute conceitos referentes à pesquisa fenomenológica do vivido ("Pesquisa do Vivido") - explorando especialmente os conceitos de "vivido" e de "pesquisa". O tema da relevância e significado da "palavra" retoma no capítulo V ("Atendimento Psicoterápico"), aliado a termos como "escuta" e "relação" (terapêutica).

O capítulo VI, denominado "Versão de Sentido", é uma apresentação e discussão de alguns aspectos relevantes do instrumento homônimo, que o Autor descreve como útil no acompanhamento terapêutico e na pesquisa

\footnotetext{
(1) Amattuzzi, M.M. (2001). Por uma Psicologia Humana, Campinas: Alínea Editora, 137p.

(2) Doutorando em Psicologia na PUC-Campinas.

Endereço para correspondência: Email: Josemarmaciel@hotmail.com - End.: Av. Marechal Carmona, 494, apto 92 (tel) 32333773 CEP 13035-510 - Campinas / SP.
} 
(cf. pág. 72). A atuação desse instrumento é ilustrada em seguida, pois ele é usado como material através do qual o Prof. Mauro delineia, no cap. VII, as "Etapas do Processo Terapêutico".

Os últimos capítulos do livro formam uma unidade, advogando um alargamento do campo de atuação da psicologia. Em primeiro lugar é trabalhado o âmbito social, através de uma breve discussão do conceito de "psicologia popular" (Capítulo IX). Em segundo lugar, o Autor ensaia uma discussão dos contextos da tratação do humano em relação com a psicologia: "pessoa", "grupo", "comunidade", "terra". Esse capítulo conclui, afirmando a necessidade de se pensar um novo paradigma (pág. 131), que integre todos esses níveis.

Na verdade, este livro do Prof. Mauro Martins Amattuzzi é como que uma coletânea de nove manifestos que tentam ajudar a pensar o trabalho e a produção de conhecimento em psicologia. Sem querer parecer polêmica ou inespecífica, esta afirmação apenas alude a uma questão incômoda para qualquer autor: "quem lerá este livro com mais proveito?". Ao mesmo tempo, surge uma resposta antecipada: os aprendizes. Mas no melhor sentido do termo, ou seja, as pessoas que pensam sinceramente ter algo a aprender com outros pesquisadores, no campo da psicologia. Isto porque o livro em questão não traz soluções prontas, resultados definitivos, quiçá eventualmente uma panorâmica de algum campo de pesquisa, ou reformulações de técnicas de atuação e pensamento. Nada disso. E esta é a sua fraqueza e a sua força, ao mesmo tempo.

Devagar, num estilo franco e pessoal, ele pode ajudar a pensar uma série de questões, com sua forma fragmentária mas instigante: quem porventura seja consciente de ainda não saber tudo sobre humanismo, sobre a finalidade, ou a vocação profunda da psicologia (do seu fazer e do seu fazer-se) e gostaria de ter alguns diálogos muito proveitosos, vai ganhar muito com os textos reunidos, se se dispuser a lê-los com atenção. Esta resenha fala um pouco de cada uma destas coisas: pontos do livro que sugerem ou se referem a discussões importantes no campo da ciência e prática da psicologia, especialmente humanista (ou que se deixa permear por dimensões humanistas, como ele observa à pág. 11); pontos abertos, arestas que podem desencorajar um pouco os leitores; finalmente, pontos que podem ser levados adiante, por leitores mais interessados e realmente comprometidos com os assuntos abordados.

O livro traz, embutido nas suas entrelinhas, todo um projeto de pensamento da psicologia enquanto conhecimento do humano: um projeto que deve ser buscado, entrevisto com atenção. Atenção ao sentido do texto, mas também às referências que vão sendo usadas. Em relação aos artigos reunidos, que escandem o curso do texto global, aparecem temas relevantes para quem queira pensar a psicologia de uma forma comprometida com o humano e com os seus valores - ou seja, quem queira levar adiante a tradição humanista em psicologia.

O primeiro destes temas é a noção de psicologia como uma escuta da fala autêntica. No fundo, parece ser este o tema que pervade todo o livro, e que pode ser posto com a pergunta, cuja resposta define se alguém é ou não humanista, em psicologia: "deve-se levar a sério o humano e os seus valores?". Isto significa não apenas um discurso de boas intenções - logo em seguida substituído por outro, de poder, que reduz o "humano" aos "sintomas", e a atuação psicológica a um ingresso mais ou menos violento na esfera da vida do outro com elementos extrínsecos a ela.

A psicologia nasceu e estabeleceu-se, sobretudo no campo da clínica, como escuta da fala, é verdade. Mas uma escuta muitas vezes regulada pelo pressuposto do estranhamento da palavra, pela cisão entre o sujeito que fala e a criança abandonada nas masmorras de sucessivos estratos defensivos 
criados pelo mesmo sujeito falante, e que está à mercê, ou dessas masmorras, ou da palavra definitiva do grande intérprete de si, o outro, que fala em nome da ("deusa"?) ciência. $\mathrm{Na}$ verdade, este "outro" seria rigorosamente falso - pois substituindo-se ao cliente, injeta os seus próprios significados naquele, desdobrando-se em mestre e discípulo. Um dos riscos da psicologia sempre foi o de tornar-se uma grande escola de narcisismo qualificado.

A leitura de Merleau-Ponty (e de Buber, para citar apenas duas referências de peso), bem situada e bem articulada em relação a esta visão negativa e desconfiada da escuta, pode ajudar a redimensionar o problema: não se trata, para o operador psi, de escutar além, por detrás, ou abaixo - mas dentro do sujeito, a partir dele e, sobretudo, com ele, como um companheiro de humanidade, um agente de resgate e "facilitação", não como um superhomem.

Nos fragmentos da dolorida fala do cliente, decifra-se a palavra autêntica, e esta não é a palavra onipotente do psicólogo. É o balbucio da autonomia insegura da nova criança, que emergirá do processo terapêutico, visto sobretudo como um processo de encontro. Neste sentido, a experiência impõe ao Prof. Mauro um sensato refrão: "A palavra foi feita para calar" (pág. 64 e passim).

O segundo tema, que atravessa o livro todo como uma costura fina, é a noção de respeito na pesquisa com seres humanos. Se o humano é realmente levado a sério, na densidade de sua palavra, então estão justificadas até certo ponto as longas repetições de excertos de entrevistas - posto que estas ilustram a complexidade da trama que subjaz às narrativas entrecortadas. Mas, e sobretudo, está mais uma vez lançado o desafio para o repensamento do que significa "objeto" na ciência psicológica. E não seria suficiente apenas mudar o vocábulo, rebatizar o "objeto" a ser pesquisado como um "sujeito", pensando que assim se teria contornado o problema de base, o de trabalhar-se com uma abstração.

Em outras palavras, e aqui se entra na discussão que parece gerar textos como o que trata da "pesquisa do vivido" (cap. IV), ou da "Versão de Sentido" (cap. VI): levar o ser humano a sério significa, para um "humanista", levá-lo a sério na produção da própria ciência psicológica. E esta, no seu resultado final, será forçosamente parecida com o ser humano que se estuda, ou seja, será invadida pela luz e ofuscada pela confusão aparente da liberdade, do reino das opções livres, repetições, do risco da inexatidão e da ambigüidade, do risco da vida real.

Este é um tema importante, e disto o prof. Mauro parece muito consciente, mencionando inclusive que a sua "VS" é objeto de várias críticas (pág. 73-4). De onde viriam estas críticas? De fora ou de dentro de uma psicologia intencionalmente humanista? Isto não fica claro, e mereceria um estudo por si só. Se de fora, então já se intui em nome de que idéias elas nascem: da precisão e da objetividade. De fato, não se é preciso com as VSs, nem confiável, não se tem resultados controláveis, deste ponto de vista. No fundo, esta crítica exterior falha ao não perceber que se trata aqui de uma outra abordagem da pesquisa científica, com método e objetivos diversos.

Isto fica mais claro no caso da crítica que vem de dentro, ou seja, de pesquisadores que querem perseguir o humano onde ele se entrega: no vivido. No ambíguo e fugidio terreno da existência e da sua leitura, no discurso de quem busca ajuda. Aqui a pergunta reguladora há que ser outra: a Versão de Sentido dá conta de toda a complexidade escondida nos fenômenos corriqueiros que encerram a circulação da vida, do existir, do posicionar-se humano no filtro refratário, isto é, simplificante e complicante da linguagem?

De fato, a levar adiante a discussão sobre o valor da Versão de Sentido como instrumento de coleta e propedêutica à tratação 
de dados, pode-se entrar em outra discussão muito abrangente, que se tem evitado durante muito tempo dentro da psicologia, talvez por tempo demais: fazer ciência e fazer ciência humana, ou do humano, ou do específico humano, não é a mesma coisa.

As conseqüências de ingressar nesta discussão podem ser de uma fecundidade - e talvez, também, de um preço - imprevisível, para o que o Prof. Mauro chama de humanização no campo da psicologia. Deve haver um motivo pelo qual o debate não se trava abertamente: 0 abismo desse preço. Não tanto um preço financeiro, mas moral. Alguém terá que dizer que a ciência do humano nem sempre tem sido uma ciência humana. Mas rever os teóricos da alienação e os próprios a priori filosóficos, repensar o lugar sociopolítico do praticante da psicologia; em outras palavras, incluir a relação humana no processo de busca de conhecimento sobre o humano pareceria uma coisa demodée - e profundamente desestabilizadora. Ao futuro, pois, o julgamento; aos "humanistas", a tarefa.

Outro elemento importante que vem no bojo do livro do Prof. Mauro é o da integração da psicologia com outros saberes. Este tema é o mais recente na sua elaboração, mas não por isso o menos instigante. Qual o papel da psicologia, e o que se pode esperar dela, num século que começa com mais uma guerra, uma queda de braço entre visões de mundo (oriente versus ocidente, Islã versus tecnologia travestida de discurso legalista) - ou seja, num século onde a subjetividade é implodida pelo terrorismo de um lado e pelo imperialismo do outro, como fenômenos-rebote? Continuar fomentando a adaptação do cidadão às cadeias de produção, aliviando os sintomas de seu desgaste e conduzindo-o até uma "sadia" aposentadoria - na linha dos funcionalismos que fizeram a fortuna dos treinamentos e a glória da psicologia como ancilla (isto é, colaboradora e aliada) do projeto desenvolvimentista ocidental? Ou tentar voltar à escuta da fala autêntica? Investir na adaptação ou na criatividade?
Mais uma vez, nas entrelinhas, o texto do prof. Mauro traz embutida toda uma discussão do que sejam a vida e ação humanas, e o seu sentido. E a resposta que ele avança é bastante lúcida, mas difícil: a psicologia deve ser a promotora de uma nova visão de mundo, na qual o homem se reintegre ao seu ambiente de forma não agressiva mas oxigenada, aberta aos outros e a si próprio.

A alternativa é clara: protagonismo ou cinismo. E no atual estado de coisas, o máximo a que se pode chegar é à projeção de "bolsões de humanismo" (págs. 126; 129). Parco como resultado, esse pode ser um momento necessário para se poder falar numa "mudança de paradigma" (cf. págs. 127-131), que deve ser bem articulada, mas sobretudo bem proposta, para não significar um retorno ao paradigma prévio ao da instauração da mentalidade científica. A psicologia não precisa de gurus, detentores de iluminações secretas e aforismos mágicos (e esta é a crítica feita, com razão, a uma forma de "humanismo" que tanto criticou Walden Two, mas sem propor nada mais consistente em seu lugar). Precisa de cientistas sim, e sensíveis à sintaxe global do que seja ser humano em profundidade. Ou seja, cientistas da complexidade global do processo humano (cf. o cap. IX).

Assim, o livro aponta para o coração de três perguntas fundamentais para quem quiser ser ajudado na missão de repensar a psicologia: o que é o humano para a psicologia? Como pesquisar este ser humano? E para quê, com que objetivo? Isto faz com que se retorne às velhas questões sobre a identidade, objeto e função da psicologia, mas com bases decididamente não utilitaristas, à luz das questões da existência real, comum, cotidiana. Isto não porque modelos atuais estejam fazendo água; pelo contrário: porque há modelos atuais tão tautológicos, "perfeitos", compactos, que podem estar deixando de fora uma massa cada vez maior de pessoas que não se sentem mais ouvidas - e cada vez mais não podem ou se recusam a pagar. Ainda bem. Se não pelo 
sótão, que venha pelo esgoto a pergunta pelo humano em psicologia. Mas que venha.

O livro é uma coletânea de reflexões de largo espectro. Mas além ou apesar disso, afirmou-se acima que possui arestas, pontas abertas, que podem até mesmo desencorajar o leitor - o que seria uma pena, dado o valor do esforço do Prof. Mauro. Deve-se anotar algo sobre estes pontos, justamente para "provocar" o Autor, para que continue trazendo à tona o que ele tenha eventualmente deixado nas entrelinhas.

É bom registrar a respeito um problema de "forma": O livro tem nove capítulos, cada um abordando temáticas válidas, e todas tendendo a fazer o trabalho que o título avança: aproximar mais os dois campos que ali se denominam como sendo o "humano" e o "psicológico". Mas trata-se de temáticas díspares, e não foram ditas, em nenhum lugar, algumas coisas importantes, como por exemplo: por que o Prof. Mauro quis escrever este livro? A pedido de alguém, de algum grupo? Por uma necessidade intrínseca? Se este foi o caso, quais os contornos desta necessidade? Como procedeu à seleção dos textos?

No início de cada capítulo tem-se uma pequena nota explicativa, no qual o que predomina é a simpatia pessoal do Autor em relação ao que dirá, além de breves explicações introdutórias. Mas falta uma integração maior, mais ampla, entre as temáticas: qual é o fio de humanismo que unifica todos os artigos, tão díspares entre si? Qual é a trama subjacente que arremata a costura do livro? Realmente, deste ponto de vista, faz falta uma Introdução. O livro conta com uma Apresentação (de autoria da Professora Vera Cury), que faz um pouco este papel, mas há um incômodo silêncio quanto à palavra do Autor.

Além disso, outro ponto aberto, um pouco até "vertiginoso", em se tratando do assunto "humanismo" em psicologia: o livro abre várias estradas, mas não trilha exaustivamente nenhuma delas. Todo o trabalho está no meio do caminho, e as intuições que vão sendo semeadas ao longo do tecido do pensamento esperam ser aproveitadas, em vários sentidos, pelo leitor. Isto é interessante, mas expõe de novo justamente o calcanhar de Aquiles do movimento humanista na psicologia. São muitas as sugestões, as intuições, as boas intenções. Mas como viabilizá-las?

Aberto como está, só se pode pensar o livro como sendo duas coisas mutuamente excludentes: um repertório de bom material reflexivo produzido pelo Prof. Mauro; ou, mais profundamente, um verdadeiro esforço que ele realizou para enuclear o que the tem sido realmente importante ao longo de sua história como clínico e como professor.

E de novo: na forma em que se encontra o texto, sem uma elaboração - de preferência longa, tematizadora e articulada, das suas finalidades, pressupostos, objetivos -, não é fácil ao leitor decidir-se em favor de uma ou outra coisa. Talvez neste caso o Autor tenha se subestimado. Mas nada de irremediável: nas entrelinhas dos pequenos parágrafos que emolduram os textos há indicações que fazem o leitor pender para a segunda hipótese. Mas apenas o leitor benévolo. E sabe-se bem que no mundo real nem todos os leitores são benévolos.

Na sua Apresentação ao livro a Professora Vera diz, com propriedade, que

"Mauro Amattuzzi tem sido (...) um psicólogo que filosofa, em suas múltiplas atividades como professor, pesquisador, conselheiro e Autor" (pág. 9).

Esta consideração é importante. Operador da psicologia com longos anos de estrada, ele tem experiência da área, coisa preciosa no meio acadêmico qualificado. Sabe-se de muitos autores que foram enredados cada vez mais pelo terreno do ensino e pesquisa, que relegaram a segundo plano a experiência profissional. Este não parece ter sido o seu caso, felizmente. No seu trabalho como psicólogo manteve realmente 
atividades em vários campos da atuação - e isso se nota em sua escrita.

Mas isto não é tudo: se por um lado, tem-se uma considerável massa de material experiencial oriundo de seus anos de atividade (ou seja, o registro típico do cientista, unido ao clínico), por outro tem-se também o esboço de categorias de pensamento, com que ele próprio começa a avaliar esse trabalho (o esforço de categorizar, típico do pensador). E é justamente neste ponto que ele ainda tem muito o que fazer - para o bem de quem está chegando agora.

Finalmente, assim, é necessário comentar o que se pode aprender com os textos do prof. Mauro. E aqui se entra no reino do "espírito": no reino das boas intenções, das motivações ou, se o leitor preferir, da ética, como formulação explícita das condições de possibilidade da escolha do trabalho em psicologia.

Em primeiro lugar, deve-se dizer - falando do ponto de partida ou do estilo -, que o registro geral da sua fala persegue o Esprit de finesse ("espírito de fineza", no sentido de Pascal), que vê a vocação profunda de cada coisa estudada, para além de dados e funções verificáveis. "Espírito de fineza" significa, para o filósofo, adicionar ao saber empírico ("geométrico") um elemento integrador que vê, para além dos dados, a sua interpenetração numa profunda intuição do significado da existência humana - o que remete a reflexão ao reino da liberdade, da transcendência e da sua dignidade única.

A ciência não pode tender à construção de um reino da total maleabilidade ou translucidez dos seus resultados, ambicionando controlar seu "objeto" como se ele ou ela fossem neutros. Menos que isso, mais humilde e realista, ela deve integrar-se na construção do cotidiano, de um reino de companheiros de humanidade. Ou, nas palavras de Pascal,

"É necessário que não se possa dizer nem: 'é matemático', nem: 'pregador', nem: 'eloqüente', mas: 'é uma pessoa de bem'; esta qualidade universal é a única que me agrada. Quando, ao ver um homem, nos recordamos do seu livro, este é um mau sinal: num homem, para evitar que uma qualidade prevaleça e o batize a partir de si mesma, eu gostaria que não nos apercebêssemos de nenhuma qualidade particular, senão no momento em que fosse necessário lançar mão dela; que não se pensasse que 'fala bem' senão no momento de se falar bem; mas que, então, fosse sempre necessário refletir-se a respeito" (Pensées, XVII).

É esta a palavra que fica na leitura do livro: trata-se de uma coletânea de textos produzida por alguém que tem muitas outras atividades e, por isso mesmo, não teve a ocasião para arredondar tanto os seus pensamentos quanto deveria. Essa coletânea representa uma trajetória existencial de quem procurou e procura pensar a psicologia com finalidades mais nobres do que as simplesmente aceitáveis de um ponto de vista pragmático. O livro reúne manifestos breves e instigantes da gênese de uma ciência que - na sua própria constituição - se recusa a estar acima, quer estar ao lado do humano em seu fazer-se, descobrir-se, integrar-se, no mais profundo significado destes termos.

Daqui fica uma interessante interlocução com o autor que parece ter inspirado boa parte dos pensamentos do livro. Maurice Merleau-Ponty, tendo estudado a ciência e suas operações, deságua (ou encalha) num provocador ceticismo, anunciando a salvação da sensibilidade humana como possível apenas no estudo da arte, se se quiser superar o tecnicismo de sua época. Ele afirma que

"A ciência manipula as coisas e renuncia a habitá-las. Fabrica para si modelos internos delas e, operando sobre esses índices ou variáveis as transformações permitidas por sua definição, só de longe em longe se defronta com o mundo atual. Ela é, sempre foi, esse pensamento 
admiravelmente ativo, engenhoso, desenvolto, esse 'parti pris', de tratar todo ser como 'objeto em geral', isto é, a um tempo como se ele nada fosse para nós e, no entanto, se achasse predestinado aos nossos artifícios" ("O Olho e o Espírito, §1").

Pois bem, isto parece uma verdade - parcial, porém: depende de que ciência se está falando. Será, porventura, possível pensar e implementar um estilo de prática de produção e gestão de conhecimento que leve a sério a história, a consciência, a sensibilidade, a dignidade e os valores humanos mais profundos? (Disto depende o futuro da consciência daqueles que se ocupam do conhecimento científico, e que se recusam a cair no cinismo de uma ciência falsamente neutra, que sabe que os seus resultados são úteis para se manipular seres humanos, vidas, empregos, chances de colocação no mundo - e ainda assim continua).

A resposta do Prof. Mauro parece ser positiva: O operador de ciência e atuação psicológicas pode ser mais que um manipulador sem princípios. Oxalá, com formadores desse estilo, a ciência não se recuse mais a apenas "habitar" as coisas. E oxalá não seja necessário aos pensadores mais sensíveis a questões sociais e humanas refugiar-se na crítica artística. Mas neste caso, especialmente no campo da ciência da psicologia, será necessário falar diferente assumindo a inglória tarefa de repensar a psicologia como uma ciência humana.

Nada mais bem-vindo que estes "manifestos". Contanto que eles não parem em si, e se transformem em carne e sangue e ossos. Mas esta resenha termina devolvendo ao Prof. Mauro uma pergunta que ele próprio fez (págs. 50-51):

"Não será que ao invés de pensarmos em possuir uma sabedoria não deveríamos pensar em sermos possuídos por uma sabedoria, da qual, no entanto, podemos nos aproximar com respeito? Que abordagem seria essa?"

Seria essa uma "psicologia humana"?... 